\title{
Defective Insulin Response of Phosphorylase Phosphatase in Insulin-resistant Humans
}

\author{
Yasuo Kida, Itamar Raz, Ryo Maeda, Bulangu L. Nyomba, Karen Stone, \\ Clifton Bogardus, James Sommercorn, and David M. Mott \\ Clinical Diabetes \& Nutrition Section, National Institutes of Diabetes, Digestive and Kidney Diseases, \\ National Institutes of Health, Phoenix, Arizona 85016
}

\begin{abstract}
Insulin-stimulated glycogen synthase activity in human muscle is reduced in insulin-resistant subjects. Insulin regulation of human muscle glycogen synthase may require activation of a type-1 protein phosphatase (PP-1). We investigated the change of phosphorylase phosphatase and glycogen synthase activities in muscle biopsies obtained during a 2-h hyperinsulinemic euglycemic clamp in 12 insulin-sensitive (group S) and 8 insulin-resistant (group R) subjects.

Fasting phosphorylase phosphatase activity was lower in group $\mathbf{R}$ than in group $S$, and did not increase significantly with insulin infusion in group $R$ until $20 \mathrm{~min}$. In group $S$, phosphorylase phosphatase was significantly stimulated by $10 \mathrm{~min}$, remaining significantly higher than in group $R$ at all time points. The insulin-mediated changes in phosphatase activities were not decreased by 3 nM okadaic acid but were completely inhibited by $1 \mu \mathrm{M}$ okadaic acid, thereby verifying that insulin-stimulated phosphorylase phosphatase is accounted for by a PP-1. Subcellular fractionation demonstrated reduced fasting PP-1 activities in both the glycogen and cytosolic fractions of muscle obtained from subjects in group $R$ compared to those in group S.

These results suggest that insulin activation of PP-1 could contribute to the stimulation of glycogen synthase by this hormone in human muscle. Lower fasting PP-1 activity in cytosol and glycogen fractions plus lower insulin-stimulated PP-1 activity could explain, in part, reduced insulin-stimulated glycogen synthase in skeletal muscle of insulin-resistant subjects. ( $J$. Clin. Invest. 1992. 89:610-617.) Key words: glucose disposal • glycogen synthase • okadaic acid • skeletal muscle • type-1 protein phosphatase
\end{abstract}

\section{Introduction}

Glucose storage via glycogen synthesis in skeletal muscle is a major determinant of insulin-mediated glucose disposal rate (1-3). A rate-limiting enzyme in glycogen synthesis is glycogen synthase, which is regulated by both reversible phosphorylation and by allosteric modifications (4-9). Phosphorylation (inactivation) of glycogen synthase is catalyzed by several pro-

Address reprint requests to Dr. Mott, Clinical Diabetes \& Nutrition Section, National Institute of Diabetes, Digestive and Kidney Diseases, 4212 N. 16th Street, Room 541, Phoenix, AZ 85016.

Received for publication 25 October 1990 and in revised form 21 August 1991.

The Journal of Clinical Investigation, Inc.

Volume 89, February 1992, 610-617 tein kinases (9-12), whereas the reverse reaction (activation) is catalyzed by protein phosphatases $(13,14)$. Insulin administration results in a rapid increase in glycogen synthase activity in both animal and human tissues $(1,3,15-21)$. Our recent data demonstrate that transient activation of glycogen synthase phosphatase is associated with insulin-mediated glycogen synthase activation in insulin-sensitive humans (21). This response was defective in insulin-resistant subjects. Based on studies of muscle glycogen synthase phosphatase in animals (13), the human enzyme should be a type-1 phosphatase (PP1), ${ }^{1}$ which is conveniently assayed using phosphorylase $a$ as a substrate. The present study demonstrates that the abnormalities in skeletal muscle glycogen synthase phosphatase activity from insulin-resistant subjects can also be detected using phosphorylase $a$ as a substrate. Based on sensitivity to inhibition by okadaic acid, the phosphatase that accounts for this abnormal activity has been identified as a PP-1. The mechanisms and regulatory proteins involved in control of PP-1 activity in the glycogen-microsomal subcellular fraction appear to be different from those in the cytosolic fraction of skeletal muscle (22). In order to further define the cause of this abnormal PP-1 activity, the subcellular location of this reduced activity was studied in muscle from insulin-resistant subjects.

\section{Methods}

Subjects. 12 insulin-sensitive subjects (group S: four Pima Indians and eight Caucasians) and 8 insulin-resistant subjects (group R: six Pima Indians and two Caucasians) participated in this study. In vivo insulinmediated glucose disposal rates $(M)$ were measured by using the hyperinsulinemic euglycemic clamp (see below). Subjects with an $M<8$ $\mathrm{mg} / \mathrm{kg}$ fat-free mass - $\mathrm{min}$ were considered to be insulin resistant. Subject characteristics are listed in Table I. Body weight $(P<0.01)$, percent body fat $(P<0.001)$, and fasting plasma insulin $(P<0.001)$ were significantly higher in group $R$ than in group $S$.

Informed consent was obtained and fitness for the study was determined by medical history, physical examination, electrocardiography, and routine blood biochemical and hematological testing. None of the subjects was taking medication. After consuming a weight-maintaining diet ( $20 \%$ protein, $50 \%$ carbohydrate, and $30 \%$ fat) for at least $2 \mathrm{~d}$, each subject had a 75-g oral glucose tolerance test. None of the subjects had diabetes mellitus but four in group $\mathbf{R}$ had impaired glucose tolerance according to the criteria established by the National Diabetes Data Group (23). Body fat as a percentage of body weight was estimated by underwater weighing with simultaneous measurement of residual lung volume (24).

Hyperinsulinemic euglycemic clamp. After at least $3 \mathrm{~d}$ on a weight maintenance diet and an overnight fast, a hyperinsulinemic euglycemic clamp was performed as previously described (21). The clamp was

1. Abbreviations used in this paper: $\mathbf{M}$, insulin-mediated glucose disposal rate; PP-1, type-1 protein phosphatase. 


\begin{tabular}{|c|c|c|c|c|c|c|c|c|}
\hline \multirow[b]{2}{*}{ No. } & \multirow[b]{2}{*}{ Sex } & \multirow[b]{2}{*}{ Age } & \multirow[b]{2}{*}{ Race } & \multirow[b]{2}{*}{$\begin{array}{l}\text { Body } \\
\text { weight }\end{array}$} & \multirow{2}{*}{$\begin{array}{l}\text { Body } \\
\text { fat }\end{array}$} & \multirow{2}{*}{$\begin{array}{c}\text { Glucose } \\
\text { disposal } \\
\text { rate }\end{array}$} & \multicolumn{2}{|c|}{ Fasting plasma } \\
\hline & & & & & & & Glucose & Insulin \\
\hline & & $y r$ & & $k g$ & $\%$ & $\begin{array}{l}\text { fat-free mass } \\
\mathrm{mg} / \mathrm{kg} \cdot \mathrm{min}\end{array}$ & $m g / d l$ & $\mu U / m l$ \\
\hline \multicolumn{9}{|l|}{ Group S } \\
\hline 1 & $\mathbf{M}$ & 26 & $\mathbf{P}$ & 65 & 22 & 14.2 & 93 & 3 \\
\hline 2 & $\mathbf{M}$ & 21 & $\mathbf{P}$ & 154 & 39 & 12.4 & 81 & 11 \\
\hline 3 & $\mathbf{M}$ & 32 & $\mathbf{P}$ & 64 & 17 & 18.7 & 96 & 2 \\
\hline 4 & $\mathbf{M}$ & 25 & $\mathbf{P}$ & 72 & 24 & 12.2 & 91 & 5 \\
\hline 5 & $\mathrm{~F}$ & 28 & $\mathrm{C}$ & 56 & 20 & 9.4 & 101 & 4 \\
\hline 6 & $\mathbf{M}$ & 26 & $\mathrm{C}$ & 66 & 8 & 14.7 & 91 & 2 \\
\hline 7 & $\mathbf{M}$ & 22 & $\mathrm{C}$ & 74 & 8 & 10.3 & 92 & 6 \\
\hline 8 & $\mathbf{M}$ & 27 & $\mathrm{C}$ & 106 & 25 & 13.2 & 87 & 1 \\
\hline 9 & $\mathbf{M}$ & 34 & $\mathrm{C}$ & 75 & 11 & 11.6 & 104 & 4 \\
\hline 10 & $\mathbf{M}$ & 35 & $\mathrm{C}$ & 99 & 20 & 11.8 & 97 & 4 \\
\hline 11 & $\mathbf{M}$ & 34 & $\mathrm{C}$ & 63 & 17 & 12.4 & 106 & 4 \\
\hline 12 & $\mathbf{M}$ & 23 & $\mathrm{C}$ & 84 & 15 & 11.7 & 92 & 14 \\
\hline Mean \pm SE & & $28 \pm 2$ & & $82 \pm 8$ & $19 \pm 3$ & $12.7 \pm 0.7$ & $98 \pm 2$ & $5 \pm 1$ \\
\hline \multicolumn{9}{|l|}{ Group R } \\
\hline 1 & $\mathbf{M}$ & 38 & $\mathbf{P}$ & 190 & 41 & 6.4 & 98 & 35 \\
\hline 2 & $\mathbf{M}$ & 43 & $\mathbf{P}$ & 148 & 42 & 5.3 & 100 & 40 \\
\hline 3 & $\mathbf{M}$ & 42 & $\mathbf{P}$ & 86 & 30 & 7.5 & 99 & 10 \\
\hline 4 & $F$ & 24 & $\mathbf{P}$ & 117 & 38 & 6.9 & 108 & 38 \\
\hline 5 & $\mathbf{M}$ & 33 & $\mathbf{P}$ & 113 & 34 & 5.9 & 97 & 19 \\
\hline 6 & $\mathbf{M}$ & 27 & $\mathbf{P}$ & 119 & 38 & 5.4 & 96 & 33 \\
\hline 7 & $\mathbf{M}$ & 39 & $\mathrm{C}$ & 174 & 42 & 6.2 & 115 & 8 \\
\hline 8 & $\mathbf{M}$ & 24 & $\mathrm{C}$ & 122 & 39 & 7.0 & 83 & 39 \\
\hline Mean \pm SE & & $34 \pm 8$ & & $134 \pm 13^{*}$ & $38 \pm 2^{\ddagger}$ & $6.3 \pm 0.3^{\ddagger}$ & $100 \pm 4$ & $28 \pm 5^{\ddagger}$ \\
\hline
\end{tabular}

Four patients in group $\mathrm{R}$ (nos. 2, 5, 6, and 7) are impaired glucose tolerant. Abbreviations for race: P, Pima Indians; C, Caucasians. Symbols: $t$ test, ${ }^{*} P<0.01 ;{ }^{\ddagger} P<0.001$ between groups.

initiated by a primed continuous high-dose insulin infusion $(600 \mathrm{mU} /$ $\min \cdot \mathrm{m}^{2}$ ) which was continued for $120 \mathrm{~min}$ while the steady-state plasma glucose was maintained at $\sim 100 \mathrm{mg} / \mathrm{dl}$. The plasma insulin concentrations were determined at $0,10,20,40,60,80$, and $120 \mathrm{~min}$. The plasma glucose concentrations were determined before the start of insulin infusion and every 2.5 or $5 \mathrm{~min}$ through the end of the clamp. The $M(\mathrm{mg} / \mathrm{kg}$ fat-free mass $\cdot \mathrm{min})$ was determined during the period from 80 to $120 \mathrm{~min}$. The basal and steady-state plasma insulin concentrations (Table II) were higher in group $\mathrm{R}$ than in group $\mathrm{S}(P<0.001$ at $0 \mathrm{~min}, P<0.05$ at $120 \mathrm{~min}$ ).

Plasma glucose and insulin concentrations were measured by the glucose oxidase method using a glucose analyzer (Beckman Instru- ments, Inc., Fullerton, CA) and by radioimmunoassay using a radioassay analyzer (Concept 4, ICN, Horsham, PA), respectively.

Muscle biopsy. Before the start of insulin infusion and at the indicated times, percutaneous muscle biopsies were taken from the quadriceps femoris muscle using a Bergstöm needle (Depuy, Phoenix, AZ) as previously described (21). Specimens $(100-200 \mathrm{mg}$ ) were frozen in liquid nitrogen within $15 \mathrm{~s}$ and stored at $-70^{\circ} \mathrm{C}$. To reduce the assay variability between specimens the biopsies were lyophilized; dissected free of blood, fat, and connective tissue; and powdered. The powder was thoroughly mixed and stored at $-70^{\circ} \mathrm{C}$ before analysis.

Enzyme assay. Glycogen synthase activity, determined by a modified method (21) of Guinovart et al. (25) and Thomas et al. (26) was

Table II. Plasma Glucose and Insulin Concentrations during Clamp

\begin{tabular}{|c|c|c|c|c|c|c|c|c|}
\hline Time $(\min )$ & 0 & 10 & 20 & 40 & 60 & 80 & 100 & 120 \\
\hline \multicolumn{9}{|c|}{ Plasma glucose $(m g / d l)^{*}$} \\
\hline Group S & $94 \pm 2$ & $99 \pm 1$ & $92 \pm 3$ & $98 \pm 3$ & $105 \pm 3$ & $103 \pm 2$ & $102 \pm 1$ & $101 \pm 1$ \\
\hline Group R & $101 \pm 3$ & $105 \pm 3$ & $106 \pm 3^{*}$ & $103 \pm 2$ & $100 \pm 1$ & $101 \pm 2$ & $101 \pm 1$ & $100 \pm 2$ \\
\hline \multicolumn{9}{|c|}{ Plasma insulin $(\mu U / m l)^{\ddagger}$} \\
\hline Group S & $7 \pm 2$ & $1,472 \pm 146$ & $1,839 \pm 223$ & $2,146 \pm 221$ & $2,159 \pm 176$ & $2,343 \pm 188$ & - & $2,513 \pm 209$ \\
\hline Group R & $28 \pm 5^{\S}$ & $1,844 \pm 146$ & $2,081 \pm 218$ & $2,573 \pm 334$ & $2,963 \pm 390$ & $3,160 \pm 407$ & - & $3,584 \pm 458^{\prime \prime}$ \\
\hline
\end{tabular}

${ }^{*}$ Mean \pm SE of samples drawn at 2.5 -5-min intervals using the 10 - or 20 -min interval before indicated times. ${ }^{\ddagger}$ Mean \pm SE of samples drawn at indicated times. Symbols: $t$ test, ${ }^{8} P<0.05$, " $P<0.001$ between groups. 
expressed as units per gram tissue dry weight. $1 \mathrm{U}$ equals $1 \mu \mathrm{mol}$ of $\left[{ }^{14} \mathrm{C}\right]$ glucose incorporated into glycogen per minute at $30^{\circ} \mathrm{C}$. The active form of glycogen synthase and total glycogen synthase were assayed at 0.17 and $7.2 \mathrm{mM}$ glucose-6-phosphate, respectively. The ratio of active form to total glycogen synthase was used as fractional glycogen synthase activity. Glycogen synthase phosphatase activity was assayed by using rabbit glycogen synthase $D$ as a substrate as described by Miller (27) with some modification (21). Phosphatase activity was calculated as the increase in the active form of glycogen synthase per minute and expressed as the change in glycogen synthase units per gram tissue dry weight. Interassay variations of glycogen synthase and glycogen synthase phosphatase were $5 \%$ and $10 \%$, respectively.

Phosphorylase phosphatase activity was determined using $\left[{ }^{32} \mathrm{P}\right]-$ phosphorylase $a$ as a substrate as described by Nimmo and Cohen (28). Dry muscle was homogenized in solution A (18 $\mu \mathrm{l} / \mathrm{mg}$ dry weight, unless otherwise indicated) containing $50 \mathrm{mM}$ Tris- $\mathrm{HCl}, 1 \mathrm{mM}$ EDTA, $50 \mathrm{mM}$ 2-mercaptoethanol, $\mathrm{pH} \mathrm{7,} \mathrm{at} 4^{\circ} \mathrm{C}$ using a Potter-Elvehjem tissue grinder (Radnoti Glass Technology Inc., Monrovia, CA). The homogenates were centrifuged at $10,000 \mathrm{~g}$ for $10 \mathrm{~min}$ at $4^{\circ} \mathrm{C}$. The resulting postmitochondrial supernatant was used for the time course study of phosphorylase phosphatase during insulin infusion. The postmitochondrial supernatant was centrifuged at $200,000 \mathrm{~g}$ for $45 \mathrm{~min}$ to separate the pellet containing glycogen and microsomes from the cytosol. The pellet was resuspended in the original volume of solution A for assay of phosphorylase phosphatase activity. This fraction will be referred to as the glycogen fraction. ${ }^{32} \mathrm{P}$-labeled phosphorylase $a$ was prepared by phosphorylation of rabbit muscle phosphorylase $b(\mathrm{P}-6635$, Sigma Chemical Co., St. Louis, MO) with phosphorylase kinase (P2014, Sigma Chemical Co.) and ${ }^{32}$ P]ATP (sp act $50-80 \mathrm{cpm} / \mathrm{pmol}$, New England Nuclear, Boston, MA) as described in Antoniw et al. (29). The phosphorylase phosphatase activity was assayed using $40 \mu \mathrm{l}$ of extract preincubated for $5 \mathrm{~min}$ at $25^{\circ} \mathrm{C}$ and mixed with $25 \mu \mathrm{l}$ of $\left.{ }^{32} \mathrm{P}\right]$ phosphorylase $a(2 \mathrm{mg} / \mathrm{ml}$ in solution A plus $0.25 \mathrm{M} \mathrm{NaCl})$ which had been preincubated $2 \mathrm{~min}$ at $25^{\circ} \mathrm{C}$. The reaction at $25^{\circ} \mathrm{C}$ was terminated after $5 \mathrm{~min}$ by adding $100 \mu \mathrm{l}$ of ice-cold $17.5 \%$ trichloroacetic acid and $100 \mu \mathrm{l}$ of $6 \mathrm{mg} / \mathrm{ml}$ bovine serum albumin. Denatured protein was removed by centrifugation at $10,000 \mathrm{~g}$, for $4 \mathrm{~min}$ and radioactivity was determined in $200 \mu$ l of the supernatant. Phosphorylase phosphatase activity is expressed as nanomoles of ${ }^{32} \mathrm{P}$ hydrolyzed per gram dry weight muscle per minute. In order to estimate the relative contributions of type 1 and type 2A protein phosphatases to the total phosphorylase phosphatase activity, the extracts were incubated with either 3 $\mathrm{nM}$ or $1 \mu \mathrm{M}$ okadaic acid (a generous gift from P. Cohen, University of Dundee, Scotland) to inactivate type 2A and types 1 plus 2A phosphatases, respectively $(30,31)$. Nonspecific dephosphorylation of phosphorylase $a$ was $<5 \%$ of the activity with extract and was subtracted from each activity. The extent of dephosphorylation of $\left[{ }^{32} \mathrm{P}\right]$ phosphorylase $a$ was $<30 \%$ of the total giving a linear response of activity with time during the 10-min incubation. Interassay variation of phosphorylase phosphatase activity was $10 \%$ and intraassay variation using the same extract was $3 \%$.

Preliminary studies demonstrated that the use of wet and lyophilized muscle gave similar results for activities of glycogen synthase, synthase phosphatase and phosphorylase phosphatase when expressed per gram dry weight (data now shown). The average dry muscle weight was $23 \%(22-24 \%)$ of wet weight. The soluble protein content of postmitochondrial supernatant was $50-60 \%$ of dry weight in both groups and was not changed by insulin infusion. Protein determination was carried out by the Bradford method (32).

Statistics. Statistical significance of the differences was analyzed with Student's paired or nonpaired $t$ test. Data were expressed as mean \pm SE unless otherwise indicated.

\section{Results}

Effect of homogenate concentration on phosphorylase phosphatase activity. The influence of homogenate concentration on the apparent phosphorylase phosphatase activities was determined in the postmitochondrial supernatant, glycogen, and cytosolic fractions as shown in Fig. 1. The extract prepared with $18 \mu \mathrm{l}$ of buffer/mg dry muscle was diluted serially. The concentration at which linearity of the assay was lost was different in the three fractions. Compared to the postmitochondrial supernatant and cytosol, linearity was maintained at higher homogenate concentrations in the glycogen fraction. In the most concentrated extracts, specific activity in the glycogen fraction was higher than in the postmitochondrial supernatant or the cytosol. Phosphorylase phosphatase activities in fasting and insulin-stimulated muscle postmitochondrial supernatant were determined using four different dilutions of the homogenate (Fig. 2). Significant insulin activation of phosphorylase phosphatase was observed only when it was assayed at the highest $(18 \mu \mathrm{l} / \mathrm{mg}$, $P<0.01)$ concentration. Because the insulin effect depended on homogenate concentration, subsequent experiments used muscle powder homogenized with $18 \mu \mathrm{l}$ of buffer/mg dry weight.

Phosphorylase phosphatase and glycogen synthase activities during insulin infusion. Changes of total and fractional glycogen synthase and phosphorylase phosphatase activities during insulin infusion are shown for the postmitochondrial supernatant in Fig. 3. In group S, total glycogen synthase activity was increased by $10 \%$ at $120 \mathrm{~min}$ (Fig. $3 A, P<0.01$ ). Differences of both basal and insulin-stimulated total glycogen synthase activities between groups were not significant. In group $\mathrm{S}$, fractional glycogen synthase activity was significantly increased by $10 \mathrm{~min}$ (Fig. $3 \mathrm{~B}, P<0.001$ ). In group $\mathrm{R}$, the increase of fractional glycogen synthase was slower and values were lower than in group $\mathrm{S}(P<0.05$ at $10 \mathrm{~min}, P<0.01$ at $120 \mathrm{~min}$ ).

In group $S$, insulin infusion resulted in a significant increase of phosphorylase phosphatase activity by 10 min reaching a maximum increase of $19 \%$ at 20 min (Fig. $3 \mathrm{C}$ ). In group $\mathrm{R}$, phosphorylase phosphatase activity did not increase at $10 \mathrm{~min}$, but increased significantly by $17 \%$ at $20 \mathrm{~min}(P<0.01)$. Both basal and insulin-stimulated phosphorylase phosphatase activities were lower in group $\mathrm{R}$ compared to group $\mathrm{S}(P<0.01$ at all time points). Results for insulin action on phosphorylase phosphatase are shown by race in Table III.

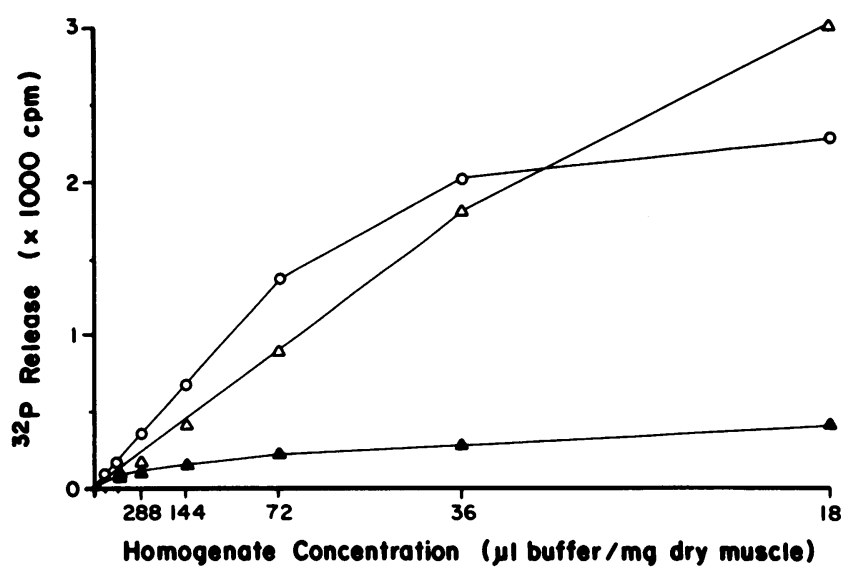

Figure 1. Effect of homogenate concentration on phosphorylase phosphatase activity in postmitochondrial supernatant (o), glycogen fraction $(\Delta)$, and cytosol $(\Delta)$. Data are means of duplicate determinations using a pool of fasting muscle from five subjects. 


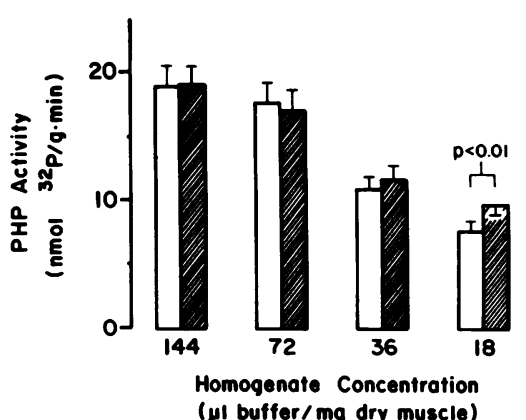

Figure 2. The influence of homogenate concentration on measured insulin activation of phosphorylase phosphatase $(P H P)$ in the postmitochondrial supernatant fraction. Phosphorylase phosphatase activities in the postmitochondrial supernatant fraction prepared from fasting (open bars) and in-

sulin-stimulated muscles (shaded bars) from five subjects were determined using four different homogenate dilutions. Significant insulin effect was observed only at $18 \mu \mathrm{l}$ of buffer/mg dry muscle.

Subcellular distribution of phosphorylase phosphatase activity and its sensitivity to okadaic acid. Phosphorylase phosphatase activities in the three subcellular fractions prepared from fasting muscle were compared in the two groups. As previously shown in Fig. 1, the relative subcellular distribution of apparent activities is partially dependent upon the concentration of the homogenate used to prepare the subcellular fractions. The apparent proportion of phosphorylase phosphatase activity is similar in both groups (Table IV). Also in both groups, activity in the glycogen fraction obtained from the postmitochondrial supernatant exceeded the activity of the intact postmitochon-

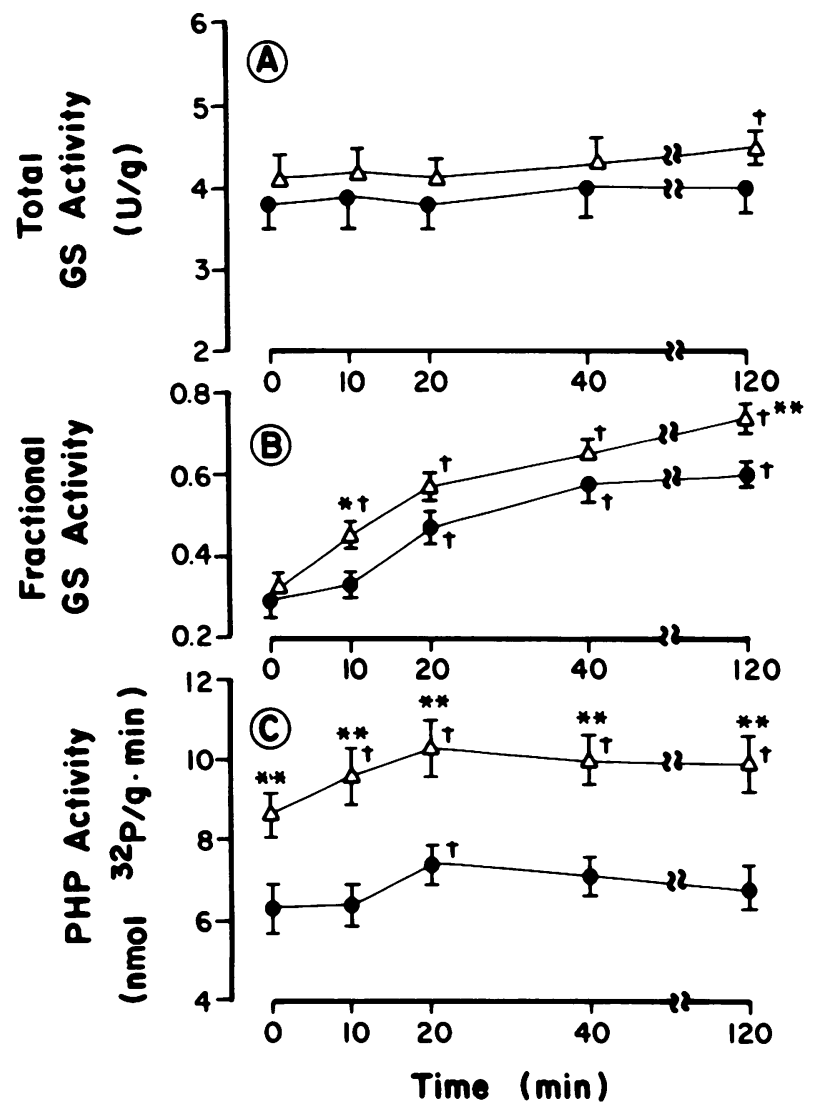

Figure 3. Change of $(A)$ total glycogen synthase $(G S)$ activity, $(B)$ glycogen synthase fractional activity, and $(C)$ phosphorylase phosphatase $(P H P)$ activity in 12 subjects from group $S(\triangle)$ and 8 subjects from group $\mathrm{R}(\bullet)$ during insulin infusion. Symbols: $t$ test, ${ }^{*} P<0.05$; ${ }^{* *} P<0.01$ between groups. Paired $t$ test, ${ }^{\dagger} P<0.01$, vs. 0 min.
Table III. Effect of Insulin on Phosphorylase

Phosphatase Activity by Race

\begin{tabular}{cccccc}
\hline & \multicolumn{2}{c}{ Caucasian } & & \multicolumn{2}{c}{ Pima Indian } \\
\cline { 2 - 3 } \cline { 5 - 6 } $\begin{array}{c}\text { Insulin } \\
\text { infusion }\end{array}$ & $\begin{array}{c}\text { Group S } \\
(n=8)\end{array}$ & $\begin{array}{c}\text { Group R } \\
(n=2)\end{array}$ & & $\begin{array}{c}\text { Group S } \\
(n=4)\end{array}$ & $\begin{array}{c}\text { Group R } \\
(n=6)\end{array}$ \\
\hline min & & \multicolumn{2}{c}{$n$ I $^{32} P / g \cdot \min$} \\
\\
0 & $8.4 \pm 0.4$ & $6.9 \pm 0.6$ & & $9.5 \pm 1.6$ & $6.1 \pm 0.7$ \\
10 & $9.2 \pm 0.4$ & $7.0 \pm 0.0^{*}$ & & $10.5 \pm 1.7$ & $6.2 \pm 0.7^{*}$ \\
20 & $10.3 \pm 0.5$ & $7.4 \pm 0.1^{*}$ & & $10.4 \pm 1.8$ & $7.4 \pm 0.6$ \\
40 & $10.0 \pm 0.5$ & $7.3 \pm 0.1^{*}$ & & $10.2 \pm 1.6$ & $7.1 \pm 0.6$ \\
120 & $9.9 \pm 0.6$ & $7.6 \pm 0.3$ & $9.8 \pm 1.6$ & $6.5 \pm 0.5$ \\
& & & & &
\end{tabular}

Symbol: $t$ test, ${ }^{*} P<0.05$ between groups of the same race.

drial supernatant. In all fractions, phosphorylase phosphatase activities in group $\mathrm{R}$ are $\sim 25 \%$ lower than in group $\mathrm{S}(P<0.01$ in postmitochondrial supernatant and glycogen fraction, $P$ $<0.05$ in cytosol fraction).

Phosphorylase phosphatase activities were also determined in subcellular fractions of fasting and insulin-stimulated muscles. Significant insulin activation of phosphorylase phosphatase was observed in the postmitochondrial supernatant and glycogen fractions, but not in cytosol (Fig. 4). After treatment with $1 \mu \mathrm{M}$ okadaic acid, no significant fasting or insulin-stimulated phosphorylase phosphatase activity could be measured in either group S (Fig. 4) or group R subjects (data not shown). Insulin stimulation of phosphorylase phosphatase activity could be observed when assayed in the presence of $3 \mathrm{nM}$ okadaic acid, suggesting that insulin stimulates primarily glycogenmicrosome-associated type 1 but not type $2 \mathrm{~A}$ protein phosphatase in human muscle postmitochondrial supernatant.

Comparison of phosphatase activity on glycogen synthase and phosphorylase after insulin infusion. Phosphorylase phosphatase and glycogen synthase phosphatase activities after insulin infusion were compared in three subjects. Activation of phosphorylase phosphatase peaked at $20 \mathrm{~min}$ and persisted throughout the insulin infusion (Fig. $5 \mathrm{~A}$ ). Activation of glycogen synthase phosphatase is transient (Fig. $5 B$ ) and peaked at $10 \mathrm{~min}$ in two subjects and $20 \mathrm{~min}$ in one subject (individual data not shown). Similar to the results shown above for phosphorylase phosphatase activity, insulin-stimulated glycogen

Table IV. Subcellular Distribution of Phosphorylase Phosphatase Activity

\begin{tabular}{cccc}
\hline & $\begin{array}{c}\text { Postmitochondrial } \\
\text { supernatant }\end{array}$ & Glycogen & Cytosol \\
\hline $\begin{array}{c}\text { Group S } \\
(n=4)\end{array}$ & $10.4 \pm 0.5$ & $17.2 \pm 0.5(165 \%)$ & $3.2 \pm 0.1(31 \%)$ \\
$\begin{array}{c}\text { Group R } \\
(n=4)\end{array}$ & $7.5 \pm 0.4^{*}$ & $13.1 \pm 0.7(175 \%)^{*}$ & $2.4 \pm 0.4(32 \%)^{\ddagger}$ \\
\end{tabular}

Phosphorylase phosphatase activities in postmitochondrial supernatant, glycogen fraction, and cytosol were determined by using fasting muscle (homogenized with $18 \mu \mathrm{l}$ buffer/mg dry muscle) from four subjects in each group. Percentages in parentheses compare activities in subcellular fractions to the postmitochondrial supernatant. Symbols: $t$ test, ${ }^{*} P<0.01,{ }^{\ddagger} P<0.05$ between groups. 


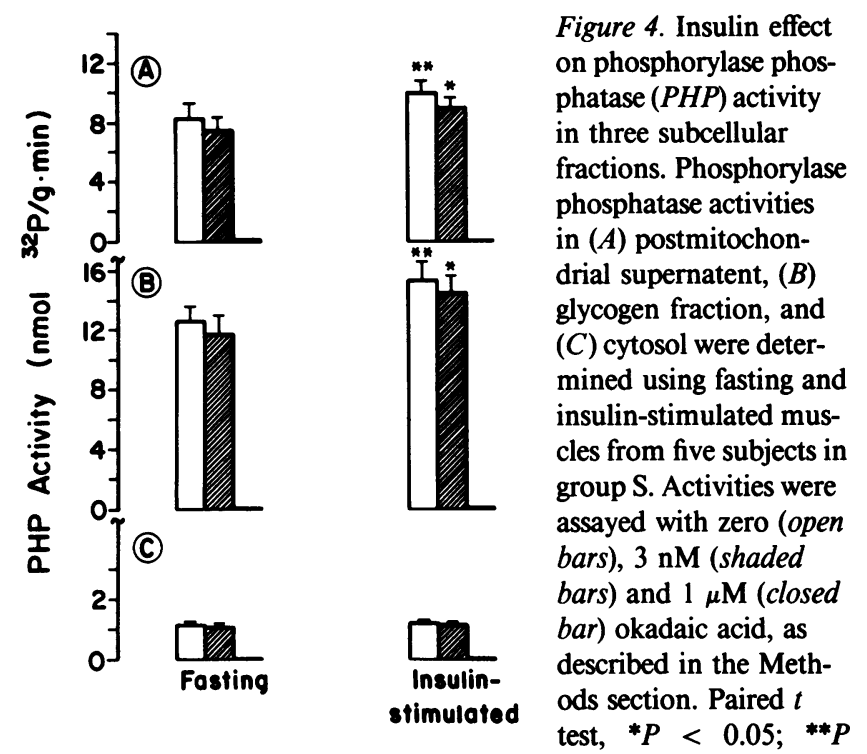

$<0.01$ between fasting and insulin-stimulated muscle.

synthase phosphatase activity was observed in the presence of 3 $\mathrm{nM}$ but not with $1 \mu \mathrm{M}$ okadaic acid, suggesting that insulin stimulation of glycogen synthase phosphatase is also mediated by activation of PP-1 (data not shown).

\section{Discussion}

Insulin-resistant subjects with low insulin-stimulated glucose disposal rates have low insulin-stimulated skeletal muscle glycogen synthase activity $(1,3)$. The data presented here also demonstrate that glycogen synthase activation by insulin is low

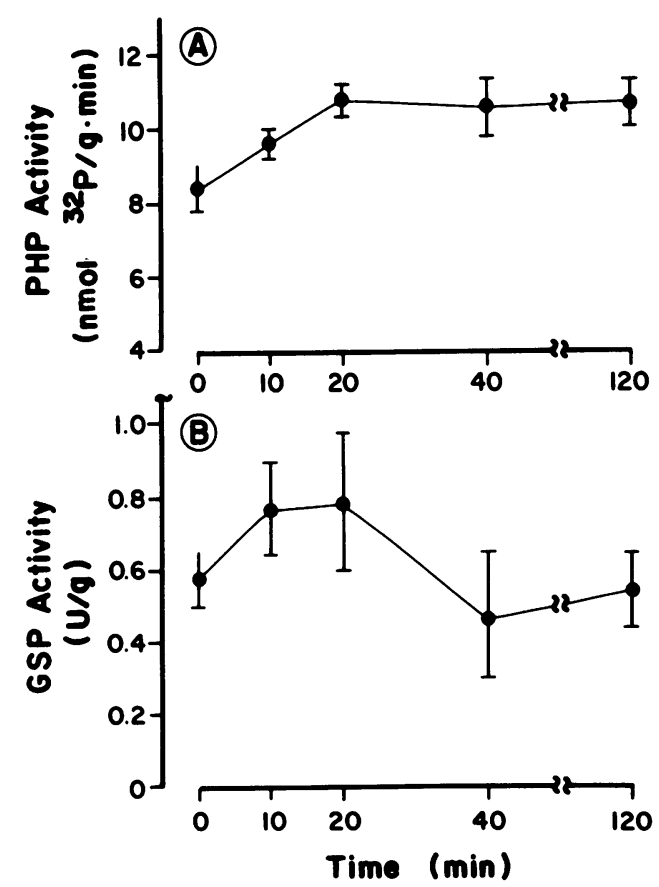

Figure 5. Comparison of $(A)$ phosphorylase phosphatase $(P H P)$, and $(B)$ glycogen synthase phosphatase (GSP) activities during insulin infusion in three insulin-sensitive subjects. in group $R$ compared with group $S$ and indicate that insulin-resistant subjects have a defect in PP-1 activity.

Glycogen synthase activity is regulated by both noncovalent allosteric interactions and by reversible phosphorylation (4-10). Phosphorylation states of several specific sites in the glycogen synthase molecule alter its activity $(10,11)$. It is well known that insulin is a potent activator of glycogen synthase in liver, fat, and muscle in animals. Stimulation of dephosphorylation by activation of a protein phosphatase $(13,14,18,20$, 21) has been proposed as a mechanism for insulin activation of glycogen synthase. We have previously reported the transient activation of skeletal muscle glycogen synthase phosphatase by insulin in humans (21). Insulin resistance was associated with a low fasting glycogen synthase phosphatase activity and a defect of its response to insulin. The previous study (21), however, did not characterize this abnormal phosphatase activity either in terms of its subcellular location or its sensitivity to okadaic acid. Here we further characterize the abnormal phosphatase activity by using phosphorylase $a$ as a substrate for the reaction. $\left[{ }^{32} \mathrm{P}\right]$ phosphorylase $a$ is a preferred substrate for measuring PP1 based on its availability in pure form, single site for dephosphorylation, and the relative simplicity of the phosphatase assay (29).

Using concentrated homogenates ( $18 \mu \mathrm{l}$ of buffer/mg dry muscle), the glycogen fraction separated from the cytosol has higher phosphorylase phosphatase activity than the original postmitochondrial supernatant (Fig. 4). This observation suggests the presence of inhibitors of PP-1 primarily in the cytosolic fraction. Insulin activation of phosphatase is also concentration dependent (Fig. 2). Significant insulin stimulation of phosphorylase phosphatase in human muscle is only observed using concentrated homogenates ( $18 \mu \mathrm{l}$ of buffer/mg dry muscle). These results may be explained by the interaction of a type-1 phosphatase catalytic subunit with insulin-sensitive regulatory proteins as discussed below.

The time courses for phosphorylase phosphatase and glycogen synthase phosphatase stimulation in response to insulin are different. In insulin-sensitive subjects, glycogen synthase phosphatase activity returned to fasting levels after peaking at 10 $\min (21)$. In order to verify this difference, three subjects were compared for phosphorylase phosphatase and glycogen synthase phosphatase activities during insulin infusion. Phosphorylase phosphatase activation in these subjects reached a plateau by $20 \mathrm{~min}$ which persisted until the end of insulin infusion (Fig. $5 \mathrm{~A}$ ). Consistent with our previous observation (21), glycogen synthase phosphatase peaked at $10 \mathrm{~min}$ in two subjects, and at $20 \mathrm{~min}$ in one subject, and then decreased to basal levels (Fig. 5 $B)$. The results suggest a feedback regulation developing after 20 min of insulin infusion which specifically inhibits PP-1 action on glycogen synthase but not on phosphorylase $a$. This regulatory mechanism would not be limited to an in vivo modification of the substrate (glycogen synthase) in that the mechanism is also capable of altering phosphatase action on the rabbit muscle glycogen synthase $D$ added to the in vitro assay mixture. Apparent independent regulation of liver PP-1 activity on phosphorylase and synthase has previously been reported. Alloxan diabetic rats had decreased glycogen synthase phosphatase activity but phosphorylase phosphatase activity was not decreased (33). The different timecourse results in Fig. 5 could be explained by distinct catalytic or regulatory subunits responsible for specific interaction with phosphorylase and syn- 
thase. Similar okadaic acid inhibition results for assays with either substrate suggest that distinct catalytic subunits would probably be isoforms of PP-1. Isoforms have been identified in tissues from rat (34) and Drosphila (35). Increasing glycogen can inhibit glycogen synthase phosphatase (15). Increases in muscle glycogen content during $40 \mathrm{~min}$ of insulin infusion, however, are $<5 \%$ and unlikely to cause such a marked inhibition of glycogen synthase phosphatase. The action of PP-1 on the two substrates may only appear to be different considering that use of synthase as a substrate required a measure of enzyme activity subject to modification by kinases and metabolites which would not necessarily alter measures of the direct dephosphorylation of phosphorylase $a$.

The phosphorylase phosphatase assay was used to compare muscle PP-1 activities in group $S$ and group $R$ after insulin administration. Fasting phosphorylase phosphatase activity in the postmitochondrial supernatant was lower by $27 \%$ in group $\mathrm{R}$ compared to group $\mathrm{S}$ (Fig. $3 \mathrm{C}$ ). Response of phosphorylase phosphatase to insulin was slower in group $\mathbf{R}$ compared to group $\mathrm{S}$. The percent stimulation above fasting at $20 \mathrm{~min}$ was similar in both groups, but insulin-stimulated phosphorylase phosphatase activity remained lower in group $R$ over the entire $2 \mathrm{~h}$. These results demonstrate that in spite of a different time course for insulin stimulated activity (Fig. 5), PP-1 assayed with either phosphorylase (Fig. 3) or synthase (21) as substrate showed reduced fasting and insulin-stimulated activities for insulin-resistant subjects. The results demonstrate that studies of abnormal PP-1 in insulin-resistant subjects can be pursued using phosphorylase $a$ as a substrate. Although the abnormality in initial insulin stimulation of PP-1 is detected by both assays, they do not apparently measure the result of identical regulatory mechanisms at least beyond the first 10-20 min of insulin infusion.

In order to study specific mechanisms for altered phosphorylase phosphatase activity in insulin-resistant humans, it is first necessary to define which characterized phosphatase is responsible for the abnormal enzyme activity. In rabbit skeletal muscle extracts, PP-1 accounts for $85-90 \%$ of the phosphorylase phosphatase activity $(36,37)$. Okadaic acid at $1-2 \mathrm{nM}$ has been previously shown to inhibit protein phosphatase $2 \mathrm{~A}$ leaving PP-1 unaffected $(30,31)$. Raising the okadaic acid to $1 \mu \mathrm{M}$ completely inhibits both type-1 and 2A protein phosphatases but not types 2B and 2C. Based on the okadaic acid inhibition of phosphatase activity observed here (Fig. 4), human muscle phosphorylase phosphatase and its insulin-stimulated activity are primarily attributed to PP-1. In addition, PP-1 is the phosphatase activity which is low in the fasting state and fails to respond normally to insulin in group $R$. Insulin stimulation of PP-1 in only the glycogen fraction (Fig. 4) suggests that this insulin action primarily utilizes regulators of PP-1 unique to the glycogen-microsomal fraction. The G-subunit of PP-1 has been described as a glycogen bound regulator of this enzyme and is discussed below.

In the fasted state, insulin-resistant subjects have reduced PP- 1 activity but glycogen synthase activity is not significantly reduced. Another apparent discrepancy between these two enzymes is the continued increase in synthase activity beyond 20 min of insulin infusion which is accompanied by a plateau (phosphorylase as substrate) or a decrease (glycogen synthase as substrate) in phosphatase activity. These observations suggest (21), that the observed insulin-mediated changes in glycogen synthase activity are the result of a coordinate regulation by multiple enzymes including changes in PP-1 activity. Insulin stimulation of glycogen synthase kinase 3 activity has been reported (38) and would be expected either to inhibit glycogen synthase by direct phosphorylation (39) or to stimulate it secondary to the phosphorylation of inhibitor 2 , which has been suggested as a mechanism for the activation of PP-1 (40). Regulation of glycogen synthase kinase 3 in human muscle has not been studied. Phosphorylation of glycogen synthase by casein kinase II does not directly alter synthase activity, but it may contribute to glycogen synthase regulation by enhancing glycogen synthase kinase 3 phosphorylation of both glycogen synthase (41) and inhibitor 2 (42). Elevated casein kinase II activity has recently been reported in muscle from both fasting and insulin-stimulated subjects with insulin resistance (43). It is not yet clear what role these two kinases, both with potential for activation or inactivation of glycogen synthase, have in explaining the abnormal glycogen synthase activity of insulin resistance.

Elevated cAMP-dependent protein kinase activity has also been reported in muscle from insulin-resistant subjects (44). In addition, inhibition of this kinase activity by insulin is reduced in insulin-resistant subjects. This elevated kinase activity in insulin-resistant subjects could contribute to reduced glycogen synthase activity as a result of the deactivation of PP-1. cAMPdependent protein kinase has been reported to phosphorylate both the G-subunit (22) and inhibitor 1 (45). Phosphorylation of the G-subunit has been reported to release the catalytic subunit of PP-1 from glycogen where it can be inactivated by the phosphorylated form of inhibitor 1 (46). Recently, an insulinstimulated kinase, which activates PP-1 bound to the Gsubunit, has been reported (47). The activities of glycogen synthase and protein phosphatase reported here, therefore, are likely to be, in part, secondary to regulation of kinase action on the G-subunit or inhibitors 1 and 2.

The postmitochondrial supernatant was fractionated into glycogen-microsomal and cytosolic fractions from group $\mathbf{R}$ subjects in order to determine if phosphatase regulators unique to either of these subcellular fractions were responsible for low PP-1 activity in insulin-resistant subjects. The results in Table III indicate a similar reduction of PP-1 activity in both glycogen and cytosolic fractions of fasting group $\mathrm{R}$ subjects. These results could be explained by $(a)$ an abnormal structure for or a reduced concentration of the PP- 1 catalytic subunit available to both glycogen and cytosolic fractions, or $(b)$ abnormally high inhibition of PP-1 by regulatory peptides in the cytosol such as inhibitors 1 or 2 plus an abnormal regulation of the G-subunit in the glycogen fraction. We have recently reported an increase in the concentration of PP-1 catalytic subunit in the postmitochondrial supernatant from insulin-resistant compared to sensitive subjects (48). The second explanation seems unlikely because trypsinization of homogenates from insulin-resistant subjects was recently reported to produce the expected stimulation $(49,50)$ of PP-1 activity but did not normalize this activity compared to control subjects (48). Trypsinization removes the effects of inhibitors 1 and 2 on PP-1 (14). This suggests that inhibitors 1 and 2 are not primary to the mechanism of abnormal PP-1 activity in insulin resistance. Abnormal G-subunit regulation of liver PP-1 activity has been reported for alloxan diabetic rats (33). A primary role for the G-subunit in causing insulin resistance seems unlikely in human muscle considering 
the similar magnitude of the defect in glycogen and cytosol fractions (Table IV). Although further studies are needed to clarify the mechanism for abnormal PP-1 activity in insulin-resistant subjects, abnormal intrinsic activity of the PP-1 catalytic subunit currently appear to be the most likely explanation.

In summary, fasting and insulin-stimulated phosphorylase phosphatase activity in human skeletal muscle is primarily mediated by a type- 1 phosphatase. Both fasting and insulin-stimulated phosphorylase phosphatase activities are reduced in the postmitochondrial supernatant of muscle from subjects with insulin resistance. Low fasting phosphatase activity in the glycogen and cytosolic fractions, and the reduced activity after insulin administration are likely to contribute to the reduced insulin-stimulated glycogen synthase activity associated with reduced insulin-stimulated glucose disposal rates in insulin-resistant subjects.

\section{Acknowledgments}

We thank the nursing staff, the dietary staff, and the technical staff for their professional assistance. We are also indebted to Rose Fields and Vicky Ossowski for their assistance with muscle biopsies and Charlesetta Lincoln for her secretarial help. Most of all, we are grateful to the volunteers for their cooperation during the studies.

\section{References}

1. Bogardus, C., S. Lillioja, K. Stone, and D. M. Mott. 1984. Correlation between muscle glycogen synthase activity and in vivo insulin action in man. $J$. Clin. Invest. 73:1185-1190.

2. Lillioja, S., D. M. Mott, J. K. Zawadzki, A. A. Young, W. G. Abbott, and C Bogardus. 1986. Glucose storage is a major determinant of in vivo "insulin resistance" in subjects with normal glucose tolerance. J. Clin. Endocrinol. Metab. 62:922-927.

3. Young, A. A., C. Bogardus, D. Wolfe-Lopez, and D. M. Mott. 1988. Muscle glycogen synthesis and disposition of infused glucose in humans with reduced rates of insulin-mediated carbohydrate storage. Diabetes. 37:303-308.

4. Danforth, W. H. 1965. Glycogen synthase activity in skeletal muscle: interconversion of two forms and control of glycogen synthesis. J. Biol. Chem. 2:588593.

5. Cohen, P. 1983. Protein phosphorylation and the control of glycogen metabolism in skeletal muscle. Philos. Trans. R. Soc. Lond. B302:13-25.

6. Cohen, P. 1986. Muscle glycogen synthase. In The Enzymes. Volume 17. P. D. Boyer and E. G. Krebs, editors. Academic Press, Inc., Orlando, FL. 461497.

7. Stalmans, W., M. Bollen, and L. Mvumbi. 1987. Control of glycogen synthesis in health and disease. Diabetes Metab. Rev. 3:127-161.

8. Roach, P. J., and J. Larner. 1976. Rabbit skeletal muscle glycogen synthase. II. Enzyme phosphorylation state and effector concentrations as interacting control parameters. J. Biol. Chem. 251:1920-1925.

9. Larner, J. 1990. Insulin and the stimulation of glycogen synthesis: the road from glycogen structure to glycogen synthase to cyclic AMP-dependent protein kinase to insulin mediators. Adv. Enzymol. Relat. Areas Mol. Biol. 63:173-231.

10. Parker, P. J., F. B. Caudwell, and P. Cohen. 1983. Glycogen synthase from rabbit skeletal muscle: effect of insulin on the state of phosphorylation of seven phosphoserine residues in vivo. Eur. J. Biochem. 130:227-234.

11. Sheorain, V. S., H. Juhl, M. Bass, and T. R. Soderling. 1983. Effects of epinephrine, diabetes, and insulin on rabbit skeletal muscle glycogen synthase. $J$. Biol. Chem. 259:7024-7030.

12. Walkenback, R. J., R. Hazen, and J. Larner. 1978. Reversible inhibition of cyclic AMP-dependent protein kinase by insulin. Mol. Cell. Biochem. 19:3141.

13. Ingebritsen, T. S., and P. Cohen. 1983. Protein phosphatase: properties and role in cellular regulation. Science (Wash. DC). 221:331-338.

14. Ballou, L. M., and E. H. Fisher. 1986. Phosphoprotein phosphatases. In The Enzymes. Volume 17. P. D. Boyer and E. G. Krebs, editors. Academic Press, Inc., Orlando, FL. 311-361.

15. Okubo, M., C. Bogardus, S. Lillioja, and D. M. Mott. 1988. Glucose-6-phosphate stimulation of human muscle glycogen synthase phosphatase. Metab. Clin. Exp. 37:1171-1176.
16. Freymond, D., C. Bogardus, M. Okubo, K. Stone, and D. M. Mott. 1988. Impaired insulin-stimulated muscle glycogen synthase activation in vivo in man is related to low fasting glycogen synthase phosphatase activity. J. Clin. Invest. 82:1503-1509.

17. Chiasson, J. L., M. R. Dietz, H. Shikama, M. Wootten, and J. H. Exton. 1980. Insulin regulation of skeletal muscle glycogen metabolism. Am. J. Physiol. 239:E69-E74.

18. Chang, L. Y., and L. C. Huang. 1980. Effects of insulin treatment on the activities of phosphoprotein phosphatase and its inhibitors. Acta. Endocrinol. 95:427-432.

19. Le Marchand-Brustel, Y., and P. Freychet. 1981. Regulation of glycogen synthase activity in the isolated mouse soleus muscle: effect of insulin, epinephrine, glucose and anti-insulin receptor antibodies. Biochim. Biophys. Acta. 67:1322.

20. Toth, B., M. Bollen, and W. Stalmans. 1988. Acute regulation of hepatic protein phosphatase by glucagon, insulin and glucose. J. Biol. Chem. 263:1406114066.

21. Kida, Y., A. E. Puente, C. Bogardus, and D. M. Mott. 1990. Insulin resistance is associated with reduced fasting and insulin-stimulated glycogen synthase phosphatase activity in human skeletal muscle. J. Clin. Invest. 85:476-481.

22. Hiraga, A., and P. Cohen. 1986. Phosphorylation of the glycogen-binding subunit of protein phosphatase-1G by cyclic-AMP-dependent protein kinase promotes translocation of the phosphatase from glycogen to cytosol in rabbit skeletal muscle. Eur. J. Biochem. 161:763-769.

23. National Diabetes Data Group. 1979. Classification and diagnosis of diabetes mellitus and other categories of glucose intolerance. Diabetes. 28:10391057.

24. Goldman, R. F., and E. R. Buskirk. 1961. A method for underwater weighing and the determination of body density. In Techniques for Measuring Body Composition. J. Brozek and A. Herschel, editors. National Academy of Sciences, National Research Council, Washington, DC. 78-89.

25. Guinovart, J. J., A. Salavert, J. Massague, C. J. Ciudad, E. Salsas, and E. Itarte. 1979. A new activity ratio assay expressing a high sensitivity to the phosphorylation state. FEBS (Fed. Eur. Biochem. Soc.) Lett. 106:284-288.

26. Thomas, J. A., K. K. Schlender, and J. Larner. 1968. A rapid filterpaper assay for UDP glucose-glycogen glycosyltransferase, including an improved biosynthesis of UDP- ${ }^{14} \mathrm{C}$-glucose. Anal. Biochem. 25:486-499.

27. Miller, T. B. 1979. Glucose activation of liver glycogen synthase: insulinmediated restoration of glucose effect in diabetic rats is blocked by protein synthesis inhibitor. Biochim. Biophys. Acta. 583:36-46.

28. Nimmo, G. A., and P. Cohen. 1978. The regulation of glycogen metabolism. Purification and characterization of protein phosphatase inhibitor-1 from rabbit skeletal muscle. Eur. J. Biochem. 87:341-351.

29. Antoniw, J. F., H. G. Nimmo, S. J. Yeaman, and P. Cohen. 1977. Comparison of the substrate specificities of protein phosphatases involved in the regulation of glycogen metabolism in rabbit skeletal muscle. Biochem. J. 162:423-433.

30. Cohen, P., S. Klumpp, and D. L. Schelling. 1989. An improved procedure for identifying and quantitating protein phosphatases in mammalian tissues. FEBS (Fed. Eur. Biochem. Soc.) Lett. 250:596-600.

31. Bialojan, C., and A. Takai. 1988. Inhibitory effect of a marine-sponge toxin, okadaic acid, on protein phosphatases: specificity and kinetics. Biochem.J. 256:283-290.

32. Bradford, M. M. 1976. A rapid and sensitive method for the quantitation of microgram quantities of protein utilizing the principle of protein-dye binding. Anal. Biochem. 72:248-254.

33. Bollen, M., and W. Stalmans. 1984. The hepatic defect in glycogen synthesis in chronic diabetes involves the G-component of synthase phosphatase. Biochem. J. 217:427-434.

34. Sasaki, K., H. Shima, Y. Kitagawa, S. Irino, T. Sugimura, and M. Nagao. 1990. Identification of members of the protein phosphatase 1 gene family in the rat and enhanced expression of protein phosphatase in gene in rat hepatocellular carcinomas. Jpn. J. Cancer Res. 81:1272-1280.

35. Dombradi, V., J. M. Axton, N. D. Brewis, E. F. DaCruz Silva, L. Alphey, and P. T. W. Cohen. 1990. Drosophila contains three genes that encode distinct isoforms of protein phosphatase 1. Eur. J. Biochem. 194:739-745.

36. Ingebritsen, T. S., A. A. Stewart, and P. Cohen. 1983. The protein phosphatase involved in cellular regulation. 6. Measurement of type-1 and type-2 protein phosphatase in extracts of mammalian tissues; an assessment of their physiological roles. Eur. J. Biochem. 132:297-307.

37. Cohen, P. 1989. The structure and regulation of protein phosphatases. Annu. Rev. Biochem. 58:453-508.

38. Yang, S., L. Ho, and T. Fung. 1988. Insulin induces activation and translocation of protein kinase $F_{A}$ (a multifunctional protein phosphatase activator) in human platelets. Biochem. Biophys. Research Commun. 151:61-69.

39. Hemmings, B. A., D. Yellowlees, J. C. Kernohan, and P. Cohen. 1981. Purification of glycogen synthase kinase 3 from rabbit skeletal muscle: copurification with the activating factor $\left(F_{A}\right)$ of the $\left(M_{z}-A T P\right)$ dependent protein phosphatase. Eur. J. Biochem. 119:443-451. 
40. Jurgensen, S., E. Shacter, C. Y-Huang, P. B. Chock, S. Yang, J. R. Vandenheede, and W. Merlevede. 1984. On the mechanism of activation of the ATP.M (II)-dependent phosphoprotein phosphatase by kinase $F_{A}$. J. Biol. Chem. 259:5864-5870.

41. Picton, C., J. Woodget, B. Hemmings, and P. Cohen. 1982. Multisite phosphorylation of glycogen synthase from rabbit skeletal muscle. FEBS (Fed. Eur. Biochem. Soc.) Lett. 150:191-196.

42. DePaoli-Roach, A. A. 1984. Synergistic phosphorylation and activation of ATP-M $\mathrm{M}_{3}$-dependent phosphoprotein phosphatase by $\mathrm{F}_{\mathrm{N}} / \mathrm{GSK}-3$ and casein $\mathbf{k i -}$ nase II. J. Biol. Chem. 259:12144-12152.

43. Maeda, R., I. Raz, F. Zurlo, and J. Sommercorn. 1991. Activation of skeletal muscle casein kinase II by insulin is not diminished in subjects with insulin resistance. J. Clin. Invest. 87:1017-1022.

44. Kida, Y., B. L. Nyomba, C. Bogardus, and D. M. Mott. 1990. Defective insulin response of CAMP dependent protein kinase in insulin-resistant humans. Diabetes. 39(Suppl. 1):254A. (Abstr.)

45. Huang, F. L., and W. H. Glinsmann. 1976. Separation and characteriza- tion of two phosphorylase phosphatase inhibitors from rabbit skeletal muscle. Eur. J. Biochem. 70:419-426.

46. Hubbard, M. J., and P. Cohen. 1989. The glycogen-binding subunit of protein phosphatase-1G from rabbit skeletal muscle: further characterization of its structure and glycogen-binding properties. Eur. J. Biochem. 180:457-465.

47. Dent, P., A. Lavoinne, S. Nakielny, F. B. Caudwell, P. Watt, and P. Cohen. 1990. The molecular mechanism by which insulin stimulates glycogen synthesis in mammalian skeletal muscle. Nature (Lond.). 348:302-308.

48. Nyomba, B. L., D. L. Brautigan, K. K. Schlender, W. Wang, C. Bogardus, and D. M. Mott. 1991. Deficiency in phosphorylase phosphatase activity despite elevated protein phosphatase type-1 catalytic subunit in skeletal muscle from insulin resistant subjects. J. Clin. Invest. 88:1540-1545.

49. Ballou, L. M., D. L. Brautigan, and E. H. Fischer. 1983. Subunit structure and activation of inactive phosphorylase phosphatase. Biochemistry. 22:33933399.

50. Gruppuso, P. A., C. L. Shriner, and D. L. Brautigan. 1987. Latent forms of type-1 protein phosphatase in rabbit skeletal muscle. Biochem. Biophys. Res Commun. 148:1174-1181. 